\title{
Prognostic factors in thyroid cancer patients
} following surgical resection: a retrospective study of optimal care strategies for postoperative complications

Hiroki Konno ( $\nabla$ konno.hiroki@nihon-u.ac.jp )

\section{Research}

Keywords: prognostic factor, thyroid cancer, impaired calcium metabolism, postoperative hypothyroidism, DPC/PDPS

Posted Date: March 19th, 2020

DOI: https://doi.org/10.21203/rs.3.rs-17910/v1

License: (9) This work is licensed under a Creative Commons Attribution 4.0 International License.

Read Full License 


\section{Abstract}

Background : This study analyzed the effects of four candidate prognostic factors on length of hospital stay among inpatients following thyroid cancer resection; specifically, age $\geq 45$ years, cervical lymph node metastasis, impaired calcium metabolism, and postoperative hypothyroidism.

Methods : This was a retrospective study reviewing 434 patients' medical and claim records $(n=434$; male $21.0 \% /$ female $79.0 \%$, age: $57.31 \pm 13.52$ ).

Results : Patients who met one of the four prognostic criteria were more likely to have a longer hospital stay using acute-care beds than corresponding cases negative for these criteria. Regression analysis indicated that patient's length of hospital stay was increased with each factor by the following rates: 1) $14.57 \%$ if 45 years or older, 2) $26.24 \%$ if positive for cervical lymph node metastasis, 3) $28.79 \%$ if positive for impaired calcium metabolism, and 4) $29.95 \%$ if positive for postoperative hypothyroidism. Moreover, estimations of cumulative probability of length of hospital stay indicate that: 1) $26.6 \%$ of the age $\geq 45$ patient group is expected to be discharged by the 7 th day in contrast to $42.9 \%$ of age $<45$ patient group $(91.0 \%, 97.4 \%$ at 14 th day); 2$) 16.1 \%$ of the cervical lymph node metastasis patient group is expected to be discharged by the 7 th day in contrast with $30.5 \%$ of non-patient group ( $83.9 \%, 92.8 \%$ at 14 th day); 3 ) $14.8 \%$ of the impaired calcium metabolism patient group is expected to be discharged by the 7 th day in contrast with $30.5 \%$ of non-patient group ( $70.4 \%, 93.6 \%$ at 14 th day), and 4$) 21.4 \%$ of the postoperative hypothyroidism patient group is expected to be discharged by the 7 th day in contrast with $29.8 \%$ of nonpatient group $(71.4 \%, 92.9 \%$ at 14 th day).

Conclusions : Disorders of calcium metabolism and postoperative hypothyroidism were the most likely postoperative complications to occur, yet these are not identified as prognostic factors in the Diagnosis Procedure Combination / Per-Diem Payment System (DPC/PDPS) framework in Japan. The findings suggest that patients with these two conditions should receive care in beds of a lower, sub-acute category, and they should be quickly transferred to such beds or, if possible, to outpatient care.

\section{Background}

Fifteen years have passed since the introduction of the Diagnosis Procedure Combination/Per-Diem Payment System (DPC/PDPS) to Japan's payment system for medical services in April 2004. The schedule, which defines standard reimbursements for acute inpatient care, was initially implemented in 82 hospitals, applying to 66,497 beds; by April 2018, it was expected to expand to 1,730 hospitals and 488,563 beds, reaching over two-thirds coverage of the total 728,393 high-acute-care beds and acute-care beds (i.e., excluding convalescent and long-term-care beds).

The DPC/PDPS provides a diagnostic category, or DPC, for every eligible disease and condition, with a "Comorbidity Complication Procedure" (CCP) matrix that specifies the final amounts for reimbursement. The per-diem prices for medical services in the matrix are set based on DPC data collected by the Ministry 
of Health, Labour and Welfare (MHLW), and are designed to gradually decrease with increased hospitalization time, as an incentive for acute care hospitals to discharge patients more quickly.

Matsuda (1) who had participated in the DPC/PDPS development project, provided the following description: "this system is a tool of standardizing and transparency of medical information, and we will be able to give an insight of medical quality and hospital management" (p. 1). As a result, the introduction of the DPC/PDPS has hastened the standardization of both costs and processes in inpatient medical care in Japan (2). Nonetheless, the inherent uncertainty of medical care means there is no guarantee that such standardization will necessarily eliminate disparities in terms of outcomes. Since April 2014, secondary diseases have been defined in the CCP matrix, a hierarchical tree diagram, resulting in additional payment categories for patients with said conditions. This update signifies that the MHLW concluded these factors to be predictive of extended hospitalization based on data provided by hospitals using DPC/PDPS. However, this also means that when other conditions occur that affect a patient's prognosis other than these secondary diseases, even if they were unavoidable or had a high risk of occurring, they might be incorrectly ascribed to poor-quality acute medical services, inadequate bed management, or insufficient regional coordination. In addition, discussions of how to improve quality of care must retrospectively consider the validity of established definitions for secondary diseases and speculate as to others.

The mortality rates due to thyroid cancer have seen a steady decline while the cancer incidence is notably increasing in most areas of the world; these trends reflect those observed in Japan (3). The outcome of thyroid cancer treatment has had an excellent prognosis with the combination of thyroidectomy and radioactive iodine-131 therapy (4). In Japan, the standard of care is thyroidectomy, and good prognostic outcomes are observed even in cases with cervical lymph node metastasis (5-8). Previous studies identified age, tumor size, stage, and cervical lymph node metastasis as prognosis factors of thyroid cancer $(5,9,10)$. Furthermore, Bergenfelz A. et al. (11) described the occurrence of re-bleeding $(2.1 \%)$, postoperative infection associated with lymph node (1.6\%), diagnosed postoperative unilateral paresis of the recurrent laryngeal nerve (3.9\%), and bilateral paresis ( $0.2 \%)$ in patients after thyroidectomy. Moreover, they described that hypocalcemia treated with vitamin $D$ analog occurred in $9.9 \%$ of the patients at the first follow-up after bilateral thyroid surgery $(n=1,648)$. The incidence of transient hypocalcemia and perennial hypocalcemia caused by hypoparathyroidism after thyroidectomy ranges from $6.9-46 \%$ (12) and from $0.9-1.6 \%$, respectively (13). Many studies described the most effective treatment for the high incidence of postoperative hypothyroidism (14-16).

Given the incidence of postoperative hypothyroidism and hypocalcemia, there is a need to understand the prognostic factors that potentially extend hospital stays due to postoperative complications.

\section{Methods}

\section{Study aim and design}


This was a retrospective study aimed to explore several candidate prognostic factors for extended hospitalization among inpatients following thyroid cancer resection. Specifically, the candidate factors of age $\geq 45$ years, cervical lymph node metastasis, impaired calcium metabolism, and postoperative hypothyroidism were investigated. Due to data limitations tumor size, range of thyroidectomy, and cancer stage could not be examined. The findings could contribute to discussions about optimal care strategies by identifying postoperative complications under hospitals' control that could worsen outcomes.

\section{Subjects}

The medical and claim data of 434 eligible cases were reviewed. Patients' medical records were analyzed if they contained a major diagnostic category (MDC) code of 100020 (Thyroid cancer) (Table 1). DPC/PDPS is classified by operation type, treatment, and secondary diseases, based on which the CCP is determined. Patients additionally needed to have undergone an operation classified under "Surgery for malignant thyroid cancer - resection (K4631) etc." in the CCP matrix for 100020: Thyroid cancer (Table 2) in the DPC/PDPS system. The six operations, including K4631, are classified in the same category as operations warranting immediate medical costs. Although the period surveyed-June 2004 to December 2008-was not recent, it was not expected to impede the analysis, as it is unlikely that the thyroid cancer patient's profile and treatment would have changed. Moreover, it was considered meaningful to be explicit about transitable patient profiles and limitations in the data resulting from patient transition to "regional packaged care" from "hospital packaged care." There are limitations in the data, because the data were collected recently for the 2004-2008 period, during which DPC/PDPS was first introduced. All possible outcomes were included, from complete remission to death. The data analyzed had already been collected by the International University of Health and Welfare (IUHW), from 21 hospitals participating in the non-profit DPC Council. The study received the approval of the International University of Health and Welfare Research Ethics Committee. 
Table 1

100020: Thyroid cancer: Tree diagram (2018-2020 edition)

\begin{tabular}{|c|c|c|c|c|}
\hline Type of operation & $\begin{array}{l}\text { Operation- } \\
\text { treatment1* }\end{array}$ & $\begin{array}{l}\text { Operation- } \\
\text { treatment2 }\end{array}$ & $\begin{array}{l}\text { Secondary } \\
\text { diseases** }\end{array}$ & \\
\hline \multirow[t]{2}{*}{ No operation } & & No & Yes/No & \multirow{6}{*}{$\begin{array}{l}\text { Comorbidity } \\
\text { Complication } \\
\text { Procedure } \\
\text { (CCP): } \\
\text { Types } 1-10\end{array}$} \\
\hline & & $\begin{array}{l}\text { Yes (types } \\
1-5)\end{array}$ & $\rightarrow$ & \\
\hline \multirow{2}{*}{$\begin{array}{l}\text { Yes: Surgery for malignant thyroid } \\
\text { cancer - resection (K4631), etc. }\end{array}$} & No & $\rightarrow$ & $\rightarrow$ & \\
\hline & Yes & $\rightarrow$ & $\rightarrow$ & \\
\hline \multirow[t]{2}{*}{ Yes: Other operations } & No & $\rightarrow$ & $\rightarrow$ & \\
\hline & Yes & $\rightarrow$ & $\rightarrow$ & \\
\hline \multicolumn{5}{|c|}{$\begin{array}{l}\text { * K386: Tracheotomy; ** If Operation: “No”, } 010120 \text { Idiopathic (mono)neuropathy or } 070040 \text { Bone } \\
\text { cancer (excluding spine); if "Yes”: } 040040 \text { Lung cancer; }{ }^{\star * *} \text { Type 1: Chemotherapy, radiotherapy, Type } \\
\text { 2: oral iodine-131, Type 3: sorafenib tosilate, Type 4: lenvatinib mesylate, Type 5: human thyrotropin } \\
\text { alfa. }\end{array}$} \\
\hline
\end{tabular}

Table 2

100020: Thyroid cancer: Surgical categories (2018-2020 edition)

$\begin{array}{lll}\text { Type of operation } & K & \text { Operation name } \\ \text { code } & \end{array}$

Surgery for malignant thyroid cancer - K461\$ Partial resection of the thyroid gland, total resection (K4631) etc. removal of thyroid tumor

K461- Endoscopic partial resection of the thyroid gland, $2 \$$ total removal of thyroid tumor

K4631 Surgery for malignant thyroid cancer - resection

K4632 Surgery for malignant thyroid cancer - total and K463- sub-total

$21 \quad$ Endoscopic surgery for malignant thyroid cancer - resection

K463- Endoscopic surgery for malignant thyroid cancer 22 - total and sub-total

Other operations

Other Other operations

\section{Procedure and statistical analysis}

First, descriptive statistics were calculated for the 434 eligible cases. The age and hospital stay distributions were analyzed using Kolmogorov-Smirnov test. Next, for each of the four candidate prognostic factors-age $\geq 45$ years, cervical lymph node metastasis, impaired calcium metabolism, and 
postoperative hypothyroidism-patients were divided into two subgroups (positive/negative status) for each variable based on their applicability, and compared in terms of descriptive statistics for the length of hospital stay. Pairwise comparisons of subgroup means were conducted using Levene's test when equal variance could be assumed, and Welch's t-test when not. These four factors were selected for three medical reasons. The first is that comorbidity and complication risks generally rise with age among thyroid cancer patients; therefore, similar to previous analyses the age cut-off of 45 years was selected ( 9 , 17). The second is that cervical lymph node involvement is a common feature of thyroid cancer; while the prognosis is generally good, metastasis is still important for severity assessments (17). The third is that surgical disruption or removal of the thyroid is associated with high risks of postoperative hypothyroidism and disorders of calcium metabolism $(15,16)$.

Finally, patients were again divided into respective subgroups according to positive/negative status for each of the four prognostic factors, and cumulative probability distributions of stay length of hospital stay were estimated using Kaplan-Meier survival analysis. The "events" assumed by the model were defined as discharge from a DPC/PDPS-designated acute-care bed or from the hospital. Pairwise comparisons of the respective subgroups were conducted using Log-rank test. IBM SPSS 26.0J for Windows was used to perform all statistical analyses.

\section{Results}

The age distribution of the entire sample was not normally distributed, and mean length of hospital stay tends to increase with age. The length of hospital stay distribution was also not normally distributed, with the most common stays lasting 8-14 days. The sample's descriptive statistics are presented in Table 3 show patients'mean age was $57.31 \pm 13.52$ with those above 60 on average requiring extended hospital stays (Fig. 1). The most common surgery based on the DPC/PDPS code was "Surgery for malignant thyroid cancer - resection: K4631" (mean patient age: $57.07 \pm 13.51$ ), followed by "Surgery for malignant thyroid cancer - total and sub-total: K4632" (57.93 \pm 14.02$)$. The majority of people had a hospital stay of 14 days (Fig. 2). 
Table 3

Descriptive statistics: Mean age and stay length

\begin{tabular}{|c|c|c|c|c|c|}
\hline $\begin{array}{l}\text { Type of } \\
\text { Operation } \\
\text { (code) }\end{array}$ & $\begin{array}{l}\text { Total } \\
\text { (K4631, etc.) }\end{array}$ & $\begin{array}{l}\text { Partial resection } \\
\text { of thyroid gland, } \\
\text { total removal of } \\
\text { thyroid tumor - } \\
\text { one side } \\
\text { (K4611) }\end{array}$ & $\begin{array}{l}\text { Partial resection } \\
\text { of thyroid gland, } \\
\text { total removal of } \\
\text { thyroid tumor - } \\
\text { both sides } \\
\text { (K4612) }\end{array}$ & $\begin{array}{l}\text { Surgery for } \\
\text { malignant } \\
\text { thyroid } \\
\text { cancer - } \\
\text { resection } \\
\text { (K4631) }\end{array}$ & $\begin{array}{l}\text { Surgery for } \\
\text { malignant } \\
\text { thyroid } \\
\text { cancer - total } \\
\text { and sub- } \\
\text { total } \\
\text { (K4632) }\end{array}$ \\
\hline Frequency & $\begin{array}{l}n=434 \\
(m: 91 / f: 343)\end{array}$ & $\begin{array}{l}n=66 \\
(m: 16 / f: 50)\end{array}$ & $\begin{array}{l}n=4 \\
(m: 1 / f: 3)\end{array}$ & $\begin{array}{l}n=201 \\
(m: 42 / f: 159)\end{array}$ & $\begin{array}{l}n=156 \\
(m: 32 / f: 124)\end{array}$ \\
\hline Age* & $\begin{array}{l}57.31 \pm \\
13.52 \\
(\mathrm{~m}: 58.96 \pm \\
13.23 \\
/ \mathrm{f}: 56.87 \pm \\
13.59)\end{array}$ & $\begin{array}{l}58.53 \pm 10.95 \\
(\mathrm{~m}: 63.06 \pm 12.55 \\
/ f: 57.08 \pm 10.11)\end{array}$ & $\begin{array}{l}61.25 \pm 2.75 \\
(\mathrm{~m}: 60.00 \pm 0.00 \\
/ f: 61.67 \pm 3.21)\end{array}$ & 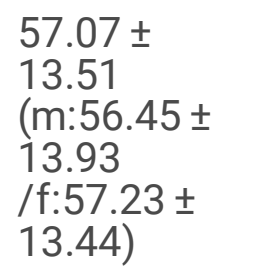 &  \\
\hline days* & $\begin{array}{l}8.95 \pm 3.69 \\
\text { (m:8.91 } \\
3.64 \\
/ f: 8.96 \pm \\
3.70)\end{array}$ & $\begin{array}{l}7.76 \pm 2.72 \\
(\mathrm{~m}: 8.31 \pm 2.55 \\
/ \mathrm{f}: 7.58 \pm 2.77)\end{array}$ & $\begin{array}{l}7.00 \pm 1.83 \\
(\mathrm{~m}: 8.00 \pm 0.00 \\
/ \mathrm{f}: 6.67 \pm 2.08)\end{array}$ & $\begin{array}{l}8.47 \pm 2.73 \\
(\mathrm{~m}: 8.07 \pm \\
2.81 \\
/ \mathrm{f}: 8.57 \pm \\
2.71)\end{array}$ & $\begin{array}{l}10.20 \pm 4.71 \\
\text { (m:10.34 } \pm \\
4.66 \\
/ f: 10.16 \pm \\
4.74)\end{array}$ \\
\hline
\end{tabular}

The findings from the subgroup analysis for the length of hospital stay for each factor suggest that overall, patients positive for a factor tended to remain in acute-care beds for considerably longer than patients in the corresponding negative subgroup (Table 4). 
Table 4

Descriptive statistics: Length of hospital stay by prognostic factor

\begin{tabular}{|c|c|c|c|c|c|c|}
\hline & \multicolumn{2}{|l|}{ Positive } & \multicolumn{3}{|l|}{ Negative } & \multirow[t]{2}{*}{ (2) } \\
\hline & frequency & days $^{(1)}$ & frequency & days $^{(1)}$ & $\mathbf{P}$ & \\
\hline Age $\geq 45$ years & $\mathrm{n}=357$ & $9.18 \pm 3.77$ & $n=77$ & $\begin{array}{l}7.87 \pm \\
3.06\end{array}$ & 0.005 & $\begin{array}{l}\star \star \star \\
(3)\end{array}$ \\
\hline $\begin{array}{l}\text { Cervical lymph node } \\
\text { metastasis }\end{array}$ & $\mathrm{n}=31$ & $\begin{array}{l}10.97 \pm \\
3.49\end{array}$ & $n=403$ & $\begin{array}{l}8.79 \pm \\
3.66\end{array}$ & 0.001 & $\begin{array}{l}\star \star \star \\
(3)\end{array}$ \\
\hline Impaired calcium metabolism & $\mathrm{n}=27$ & $\begin{array}{l}11.78 \pm \\
4.33\end{array}$ & $n=407$ & $\begin{array}{l}8.76 \pm \\
3.57\end{array}$ & 0.001 & $\begin{array}{l}\star * * \\
(4)\end{array}$ \\
\hline Postoperative hypothyroidism & $\mathrm{n}=14$ & $\begin{array}{l}12.36 \pm \\
3.99\end{array}$ & $n=420$ & $\begin{array}{l}8.83 \pm \\
3.63\end{array}$ & 0.000 & $\begin{array}{l}* \star * \\
(3)\end{array}$ \\
\hline $\begin{array}{l}\text { (1) Days (mean } \pm \text { SD); (2) Sigr } \\
0.10) ; \text { (3) Levene's test, (4) We }\end{array}$ & $\begin{array}{l}\text { ant differe } \\
\text { t test. }\end{array}$ & indicate & $\star \star \star * \quad(p<0$ & $\star \star *(p$ & , and & \\
\hline
\end{tabular}

The estimated effects of the four prognostic factors on the study outcome-length of hospital stay in days-are presented in Table 5. The estimation equation was as follows:

$\ln D_{\mathrm{i}}=1.958 \otimes 0.136 \mathrm{~A} \square 0.233 \mathrm{CL} \square 0.253 \mathrm{CM} \square 0.262 \mathrm{PH} \square \varepsilon_{\mathrm{i}}$

A: age, CL: cervical lymph node metastasis, $\mathrm{CM}$ : impaired calcium metabolism, $\mathrm{PH}$ : postoperative hypothyroidism

Table 5

Estimation results of length of hospital stay associated prognostic factors with an adjusted $R^{2}$ of 0.511

\begin{tabular}{|c|c|c|c|c|c|}
\hline$(n=434)$ & Coefficient & Standard Error & t value & $\mathrm{p}$ value & \\
\hline Intercept & 1.958 & 0.045 & 43.282 & $<0.001$ & \\
\hline Age $\geq 45$ years (dummy) & 0.136 & 0.050 & 2.736 & 0.006 & *** \\
\hline Cervical lymph node metastasis (dummy) & 0.233 & 0.073 & 3.172 & 0.002 & *** \\
\hline Impaired calcium metabolism (dummy) & 0.253 & 0.079 & 3.179 & 0.002 & *** \\
\hline Postoperative hypothyroidism (dummy) & 0.262 & 0.109 & 2.414 & 0.016 & ** \\
\hline
\end{tabular}

All variables were found to be statistically significant. In addition, the patient's length of hospital stay was increased by each factor; the following rates were obtained by exponentiating the respective unstandardized coefficient: 1) $14.57 \%$ if 45 years or older in age, 2) $26.24 \%$ if positive for cervical lymph 
node metastasis, 3) $28.79 \%$ if positive for impaired calcium metabolism, and 4) $29.95 \%$ if positive for postoperative hypothyroidism.

Based on these estimates, patients were again divided into respective subgroups according to positive/negative status for each of the four factors, and their length of hospital stay compared utilizing cumulative probability curves. Overall, the profiles show significant differences between each pair, with "positive" patients most likely to remain in acute inpatient care at any given time than "negative" patients for each factor. The details of the results were as follows:

1. It is expected that $26.6 \%$ of the aged $\geq 45$ patient group would be discharged by the $7^{\text {th }}$ day of hospitalization in contrast to $42.9 \%$ of the age $<45$ patient group discharged a week later $(91.0 \%$, $97.4 \%$ at $14^{\text {th }}$ day) (Figure 3 );

2. It is expected that $16.1 \%$ of the cervical lymph node metastasis patient group would be discharged by the $7^{\text {th }}$ day of hospitalization in contrast to $30.5 \%$ of the non-lymph node patient group discharged a week later $\left(83.9 \%, 92.8 \%\right.$ at $14^{\text {th }}$ day) (Figure 4$)$;

3. It is expected that $14.8 \%$ of the impaired calcium metabolism patient group would be discharged by the $7^{\text {th }}$ day of hospitalization in contrast to $30.5 \%$ of the non-impaired patient group discharged a week later $\left(70.4 \%, 93.6 \%\right.$ at $14^{\text {th }}$ day) (Figure 5$)$; and

4. It is expected that $21.4 \%$ of the postoperative hypothyroidism patient group would be discharged by the $7^{\text {th }}$ of hospitalization day in contrast to $29.8 \%$ of the non-postoperative hypothyroidism patient group discharged a week later $\left(71.4 \%, 92.9 \%\right.$ at $14^{\text {th }}$ day) (Figure 6$)$.

\section{Discussion}

In this study, patient clinical data were retrospectively analyzed with the objective of evaluating several potential prognostic factors in thyroid cancer patients eligible for surgical intervention. The primary outcome-days until discharge from hospital-was found to be prolonged in the presence of all four factors tested: age $\geq 45$ years, cervical lymph node metastasis, impaired calcium metabolism, and postoperative hypothyroidism.

Japan's DPC/PDPS provides an incentive for hospitals to systematically discharge patients more quickly. However, none of the four factors examined here are avoidable ones. First, patient age cannot be controlled by the hospital. Second, if already present at admission, complications due to lymph nodes cannot be avoided by any hospital, even by the highest quality of care. Nonetheless, one can still argue for its validity as an indicator of cancer staging in the DPC/PDPS, which assesses fees based in part on disease severity. The incidence of Disorders of calcium metabolism and postoperative hypothyroidism, on the other hand, lack designated payment categories in the CCP matrix; the DPC/PDPS records them separately in the field of secondary diseases, despite the high likelihood of these postoperative complications following thyroid cancer resection. 
Disorders of calcium metabolism had the strongest connection with thyroid cancer resection, giving it the highest explanatory power among the factors examined, and is consistent with the findings described by Bilezikian et al. (13) and Suzuki and Takeuchi (12). These conditions develop when the gland is damaged or lost, causing calcium serum levels to drop dramatically and a resulting shortage of thyroid hormone. Symptoms include numbness in the hands and lips, systemic spasms, delirium, and hallucinations; severe cases may go on to develop heart failure or encephalopathy. In addition, thyroid cancer resection is assumed to have a strong association with postoperative hypothyroidism. Loss of the gland leads to a shortage of thyroid hormone, slowing metabolic function throughout the body: psychological symptoms that may be observed include drowsiness, impaired memory, depression, and lethargy. Other symptoms can include dry skin, hair loss, local swelling, and hoarseness due to cellular metabolic disruption, decreased GI motility (constipation), cardiac dysfunction (bradycardia), and general malaise $(15,16)$. This prognostic factor especially has high explanatory power among patients not treated by surgical intervention, in whom it develops as sudden hypothyroidism.

The exclusion of these conditions from the CCP matrix may reflect a decision by the MHLW that these postoperative complications should not be treated in DPC/PDPS-designated beds, for acute inpatient care. However, Matsuda (2) who had participated in the DPC/PDPS development project describes "length of hospital stay merely indicates one of the indexes of outcome" (p. 142), and "appropriate length of hospital stay should be determined by medical diagnosis and the patient's intention" (p. 142). The outcome of this study suggests that the incidence of these two conditions after thyroid cancer resection can be interpreted to reveal a mismatch between these patients' clinical status and bed function as beds covered by DPC/PDPS is for acute inpatient care. The survey data was collected during the period in which DPC/PDPS was first introduced and characterized by "hospital packaged care," not during the recent era of "regional packaged care," which has produced great strides in community-based integrated care.

This is likely why patients with these two conditions continued to receive treatment in beds intended for acute inpatient care during this time frame. Nonetheless, these patients should still be receiving care in beds of a lower, sub-acute category, given the ideal of matching patients of a given clinical status with hospital beds of a suitable category based on the stages of political promotion of regional packaged care and functional differentiation of hospitals in Japan (17). Were this possible, developing impaired calcium metabolism or postoperative hypothyroidism after an operation could reduce the average stay of such patients in acute-care beds. Matsuda (1) states that "medical care, long-term care, and prevention of disease should not be affected by regional conditions and accessibility," (p. 1) and Chikugo (18) states that "one of the barriers of promoting community-based integrated care is shortage of care staff in many areas in Japan" (p. 81).

Patients with impaired calcium metabolism or postoperative hypothyroidism after an operation cannot always be discharged earlier from all hospitals because of staffing issues and the availability of suitable hospital beds. However, the study had some limitations: 1) Inherent limitations and risk of bias due to the study design were present i.e., registry-based and database studies (with retrospective design), 2) the 
data presented is from 2004 to 2008 and may not be representative of current practices or population characteristics, 3 ) there might be residual confounding given that the regression models contain only a few variables i.e., not including tumor size, range of thyroidectomy, and stage of cancer, and 4) the results cannot be generalized to other populations (the necessity of re-examining national data). Although there were limitations to this study, four prognostic factors of prolonged hospitalization following surgery for thyroid cancer were identified, namely: age $\geq 45$ years, cervical lymph node metastasis, impaired calcium metabolism, and postoperative hypothyroidism. The findings support the conclusion that patients who develop disorders of calcium metabolism or postoperative hypothyroidism after an operation should be transferred to a different bed type or, if possible, to outpatient care. The author hopes that the study findings give readers an opportunity to re-consider optimal acute care strategies in Japan.

\section{Conclusions}

This study analyzed the effects of four candidate prognostic factors on hospital stay length among patients indicated for surgery to treat thyroid cancer: age $\geq 45$ years, cervical lymph node metastasis, impaired calcium metabolism, and postoperative hypothyroidism. Patients meeting one of these criteria were more likely to stay in acute-care beds for longer than corresponding cases negative for the criterion. Notably, the findings suggest that patients who develop disorders of calcium metabolism or postoperative hypothyroidism after an operation should be transferred to a different bed type or, if possible, to outpatient care, to ensure that patients of a given clinical status are matched with hospital beds of a suitable category.

\section{Abbreviations}

DPC/PDPS

Diagnosis Procedure Combination / Per-Diem Payment System

CCP

Comorbidity Complication Procedure

MHLW

Ministry of Health, Labour and Welfare

\section{Declarations}

Ethics approval and consent to participate: The study received the approval of the International University of Health and Welfare Research Ethics Committee (approval number 15-lo-11). The requirement for informed consent was waived by the ethics committee due to the retrospective design of the study

Consent for publication: Not applicable

Availability of data and materials: The datasets used and analyzed during the current study are available from the corresponding author on reasonable request. 
Competing interests: The author declares that they have no competing interests.

Funding: Not applicable

Authors' contributions: Not applicable

Acknowledgments: We would like to thank Editage (www.editage.com) for English language editing.

\section{References}

1. Matsuda S. Heading towards implementation of regional packaged care, The quarterly of social security research. 2019;39:130-43.

2. Matsuda S. Current state and problems of diagnosis procedure combination/per-diem payment system in Japan. Journal of the Japan Society for Healthcare Administration. 2003;56:45.

3. La Vecchia C, Malvezzi M, Bosetti C, Garavello W, Bertuccio P, Levi F, et al. Thyroid cancer mortality and incidence: a global overview. Int J Cancer. 2015;136:2187-95.

4. Bilimoria YK, Bentrem JD, Ko YC, Stewart AK, Winchester DP, Talamonti MS, et al. Extent of surgery affects survival for papillary thyroid cancer. Ann Surg. 2007;246:375-84.

5. Oba T, Hanamura T, Okada T, Watanabe T, Kanai T, Maeno K. et al. A retrospective analysis of association between extent of thyroidectomy and recurrence and prognosis of well differentiated papillary thyroid carcinoma. Official Journal of the Japan Association of Endocrine Surgeons and the Japanese Society of Thyroid Surgery. 2014;31:214-8.

6. Yoshida A, Matuzu K, Kojima I, Mukaebashi T, Nakayama A, Yanagi H, et al. Treatment outcome of papillary thyroid carcinoma in our institution and optimal initial surgical strategy. Official Journal of the Japan Association of Endocrine Surgeons and the Japanese Society of Thyroid Surgery. 2012;29:126-30.

7. Tsuzuki H, Fujieda S, Ohtsubo T, Kubo S, Sakashita M, Oh M, et al. Treatment strategy for T4N1 thyroid papillary carcinoma based upon our clinical experience. Nihon Jibiinkoka Gakkai Kaiho [Journal of Otolaryngology of Japan]. 2003;106:730-8.

8. Ito $Y$, Masuoka $H$, Fukushima $M$, Inoue $H$, Kihara $M$, Tomoda $C$, et al. Excellent prognosis of patients with solitary T1NOMO papillary thyroid carcinoma who underwent thyroidectomy and elective lymph node dissection without radioiodine therapy. World J Surg. 2010;34:1285-90.

9. Sugino K, Kameyama K, Nagahama M, Kitagawa W, Shibuya H, Ohkuma K, et al. Prognosis of follicular thyroid carcinoma. Official Journal of the Japan Association of Endocrine Surgeons and the Japanese Society of Thyroid Surgery. 2013;30:7-12.

10. Ito Y, Miyauchi A. Diagnosis and treatment of thyroid tumors: approach as an internist, Journal of the Japan Thyroid Association. 2010;1:114-7.

11. Bergenfelz A, Jansson S, Kristoffersson A, Mårtensson H, Reihnér E, Wallin G, et al. Complications to thyroid surgery: results as reported in a database from a multicenter audit comprising 3,660 patients. 
Langenbeck's Arch Surg. 2008;393:667-73.

12. Suzuki H, Takeuchi Y. Management of hypoparathyroidism after thyroid surgery. Official Journal of the Japan Association of Endocrine Surgeons and the Japanese Society of Thyroid Surgery. 2014;31:2-4.

13. Bilezikian JP, Khan A, Potts JT Jr, Brandi ML, Clarke BL, Shoback D, et al. Hypoparathyroidism in the adult: epidemiology, diagnosis, pathophysiology, target organ involvement, treatment, and challenges for future research. J BoneMiner Res. 2011;26:2317-37.

14. Su SY, Grodski S, Serpell JW. Hypothyroidism following hemithyroidectomy: a retrospective review. Ann Surg. 2009;250:991-4.

15. Ahn D, Ho SJ, Han JJ. Hypothyroidism following hemithyroidectomy: incidence, risk factors, and clinical characteristics. J Clin Endocrinol Metab. 2016;101:1.

16. Shishiba $Y$, Imai T, Kanmori M, Kurihara H, Tori M, Noguchi $H$, et al. Prevalence of postsurgical hypoparathyroidism in Japan: Estimated from the data of multiple institutes. Official Journal of the Japan Association of Endocrine Surgeons and the Japanese Society of Thyroid Surgery. 2017;34:516.

17. Kawagoe M. Current state and problems of community-based comprehensive care system in Japan. The review of comparative social security research. 2008;162:4-15.

18. Chikugo I. Issues and the prospect of integrated care system. Kawasaki Med Welf J. 2016;26:79-83.

\section{Figures}




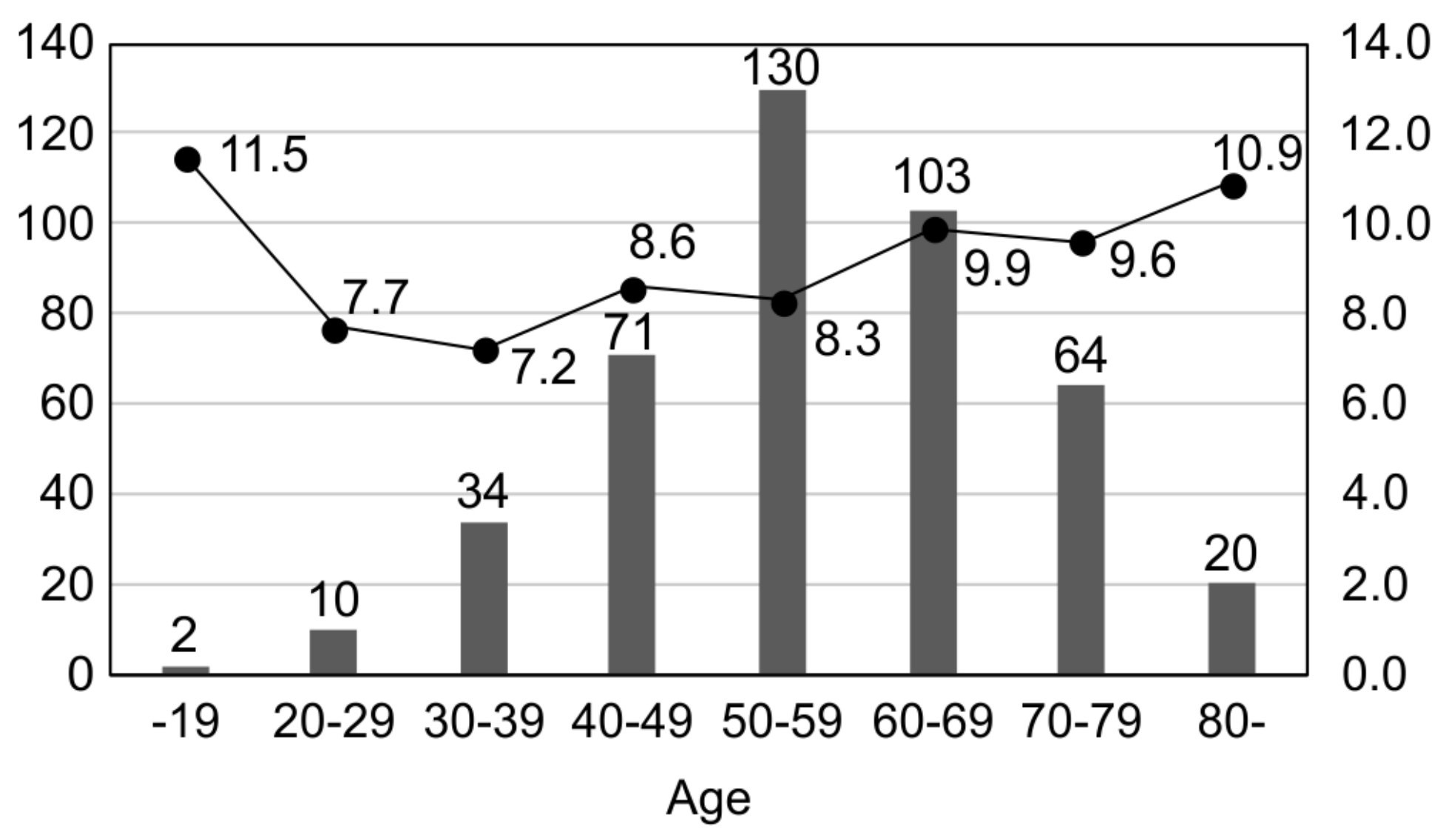

Figure 1

Frequency and average days of hospital stay by age $(n=434)$ 


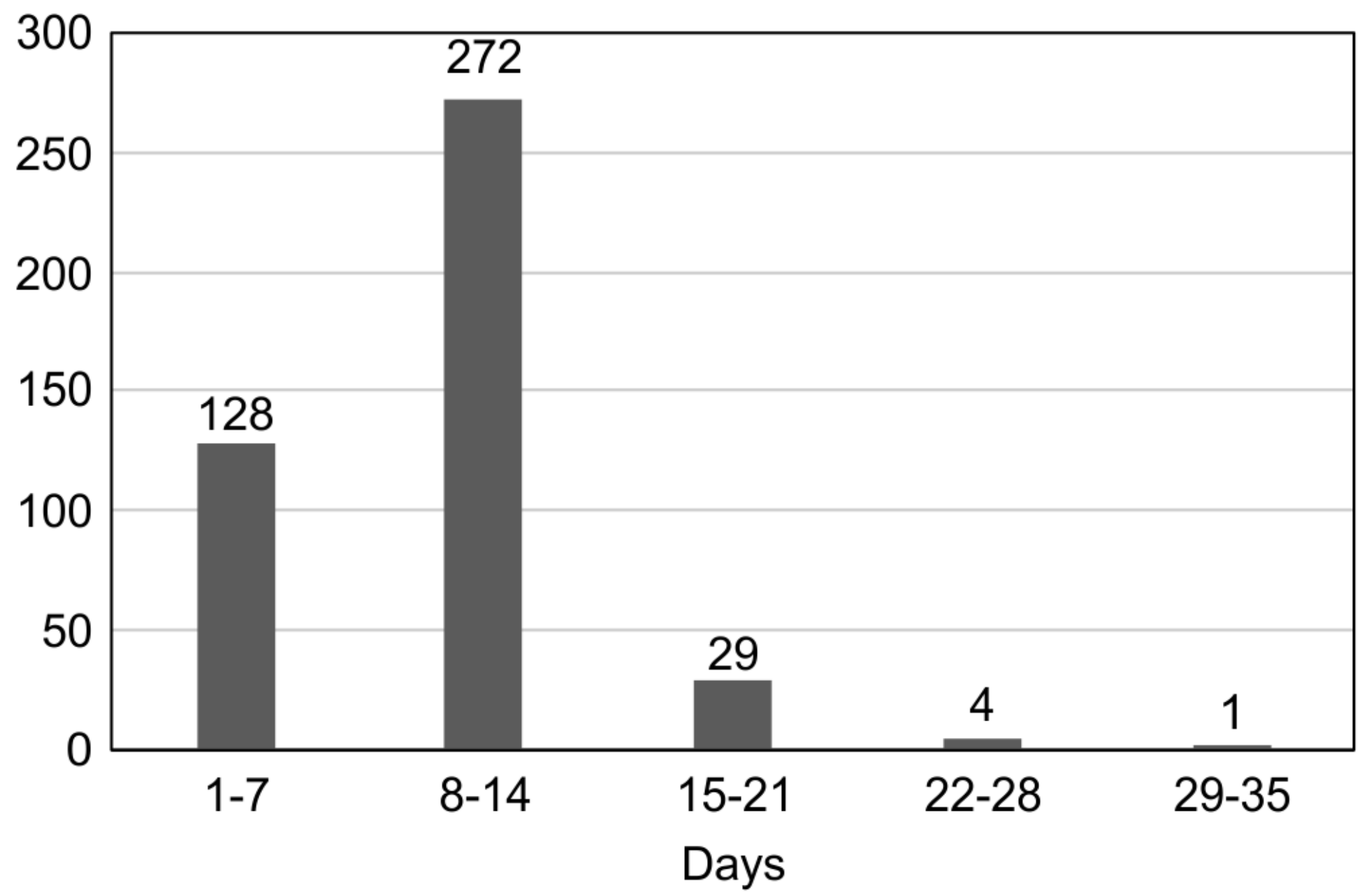

Figure 2

Frequency of hospital stay by week $(n=434)$ 


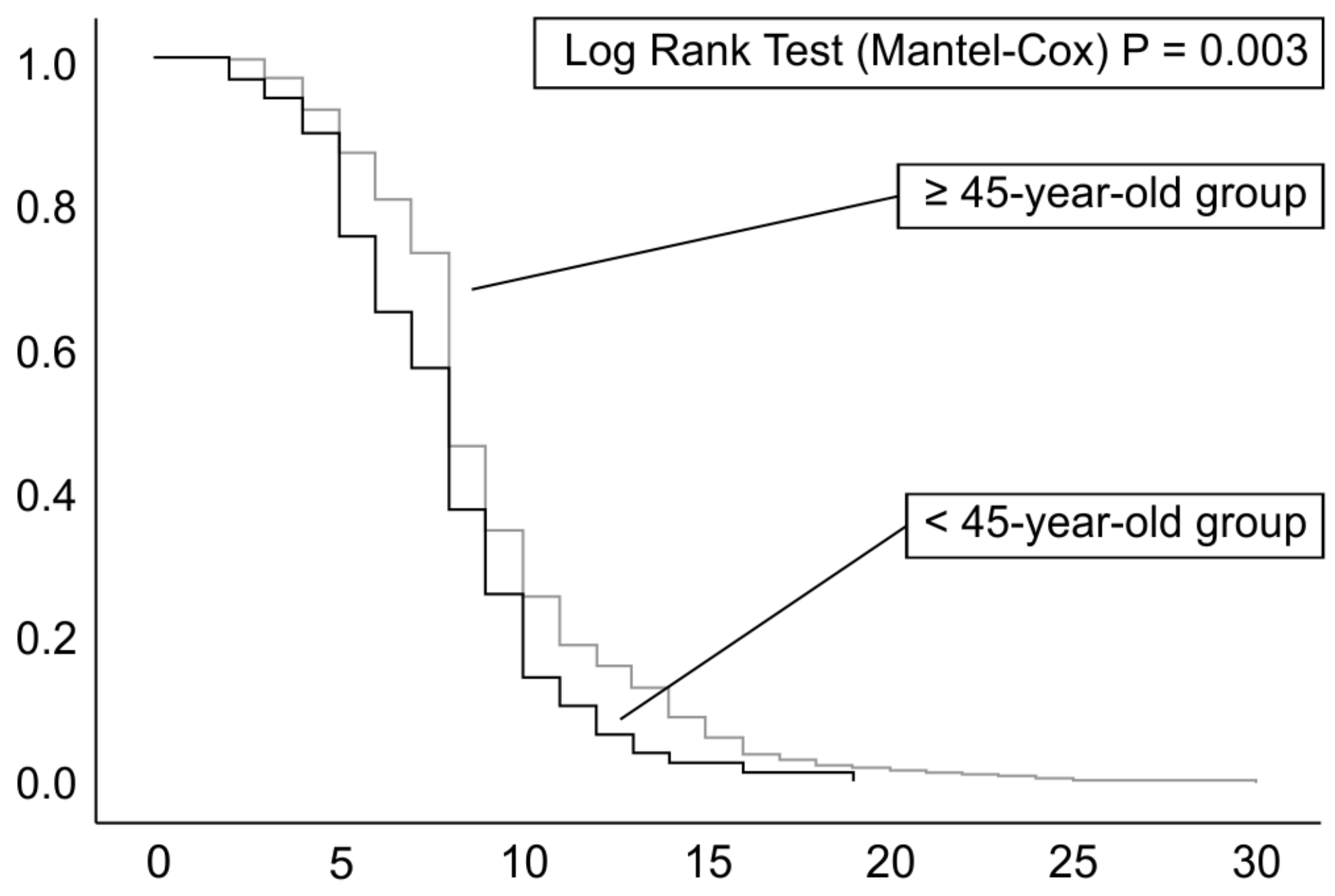

Figure 3

Cumulative probability: Aged $\geq 45$ years 


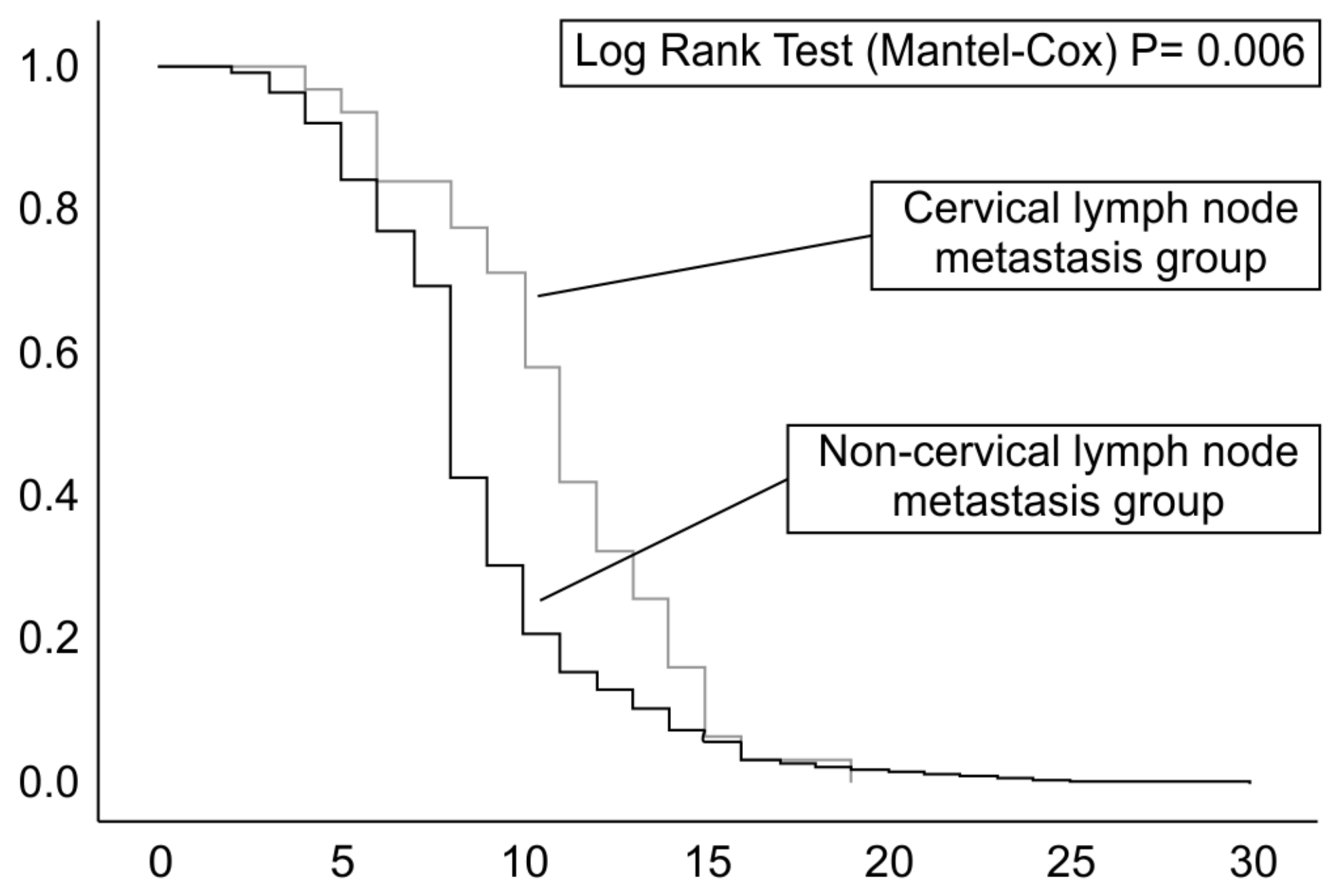

Figure 4

Cumulative probability: Cervical lymph node metastasis 


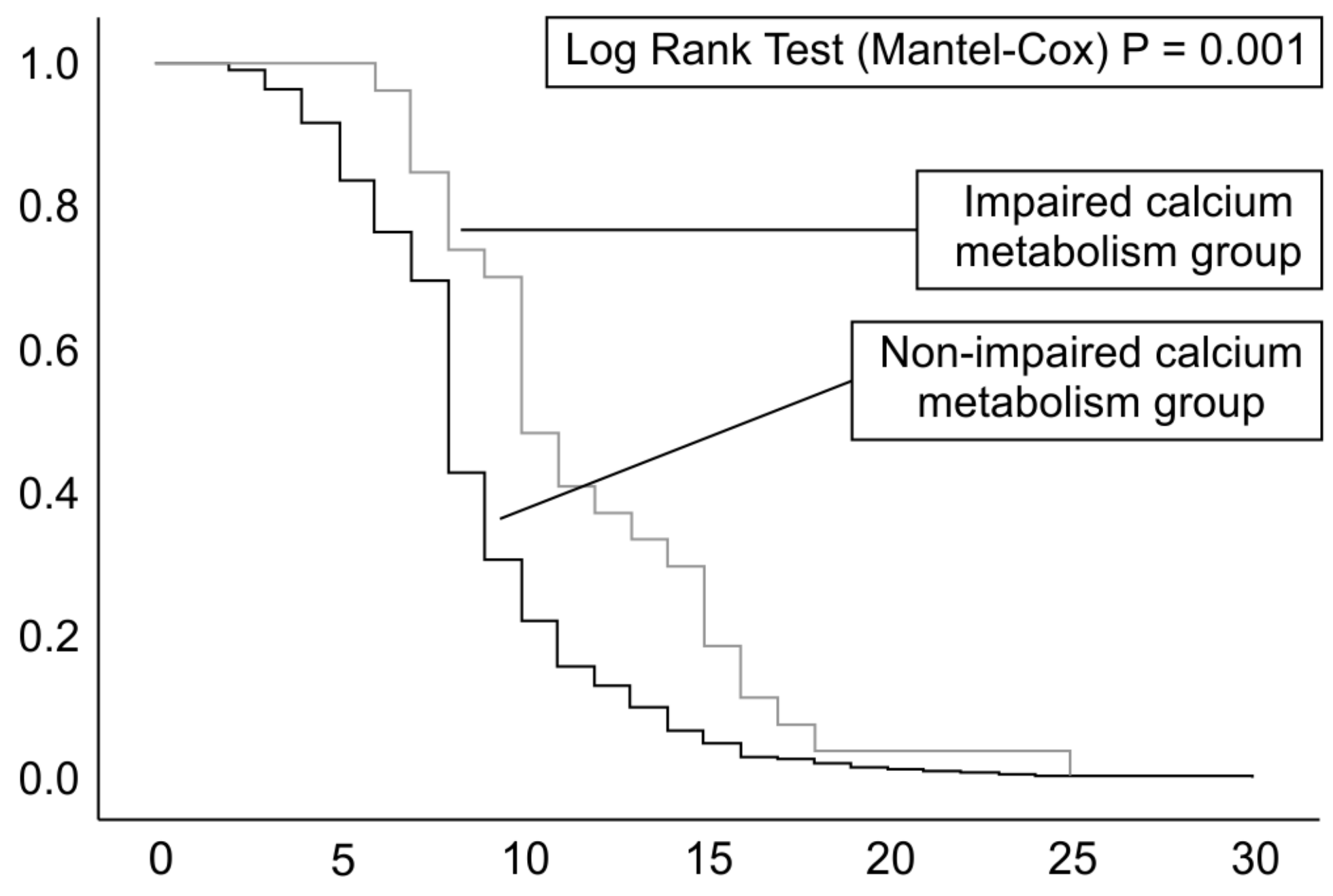

Figure 5

Cumulative probability: Impaired calcium metabolism 


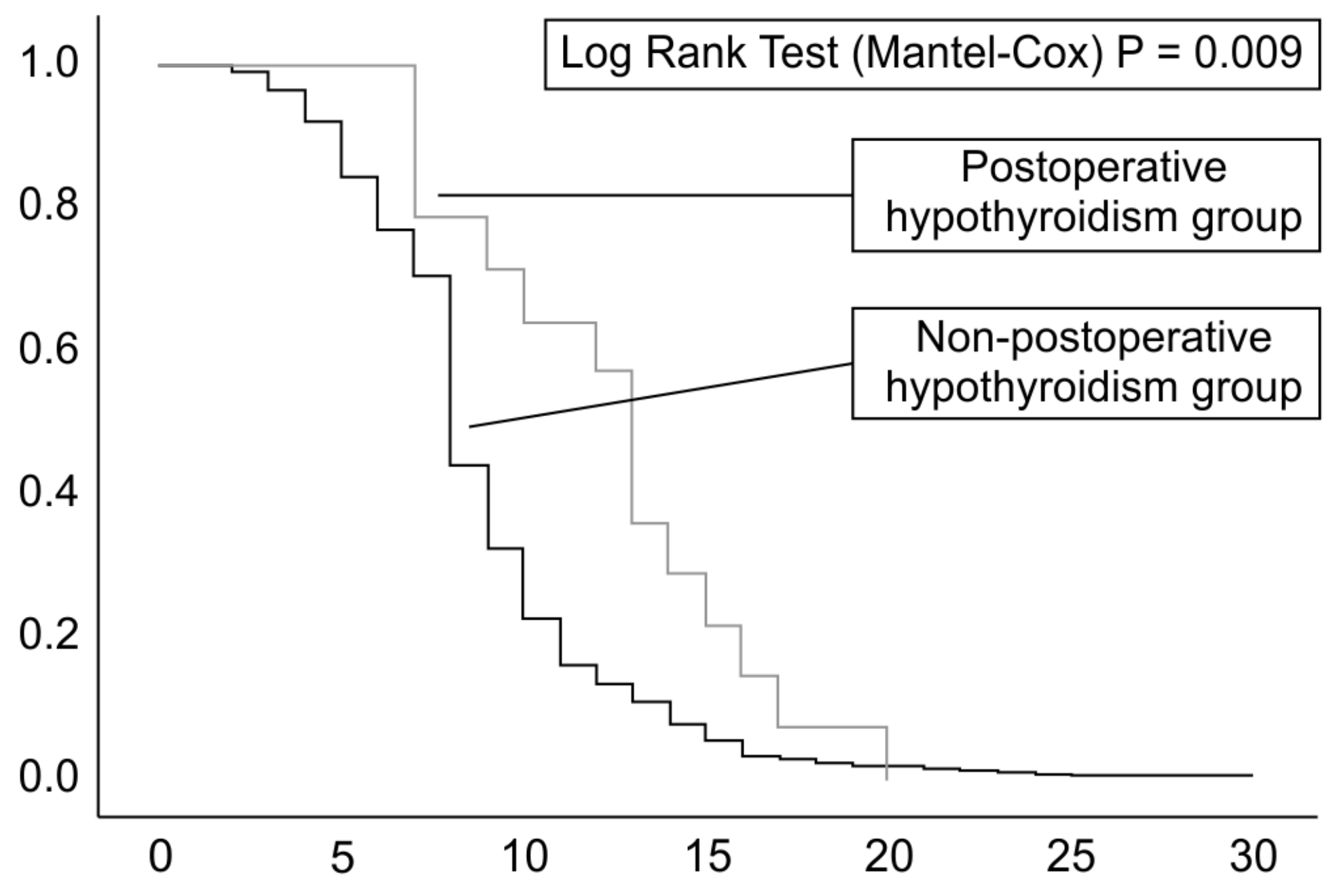

Figure 6

Cumulative probability: Postoperative hypothyroidism 